\title{
Memória Prospectiva e Epilepsia no Lobo Frontal
}

\author{
Prospective Memory and Frontal Lobe Epilepsy
}

\author{
Adriana Machado Vasques', Roberta de Figueiredo Gomes², \\ Angela Maria de Freitas ${ }^{3}$
}

\section{RESUMO}

Introduçáo. Pacientes com Epilepsia do Lobo Frontal (ELF), embora geralmentedemonstrem um bom desempenho nos testes tradicionais de memória, apresentam muitos esquecimentos na vida diária, comprometendo sua vida acadêmica, profissional e social. Tais esquecimentos referem-se à Memória Prospectiva (MP), que consiste em recordar, no momento adequado uma intenção a desempenhar no futuro. Objetivo. Este artigo tem como objetivo revisar estudos relacionados à memória prospectiva e seu funcionamento em pacientes com epilepsia de lobo frontal (ELF). Método. Revisão bibliográfica, utilizando artigos de jornais indexados no Scielo e Medline, de 2007 a 2011 no idioma inglês, com os unitermos memória, memória prospectiva, epilepsiae lobo frontal. Resultados. Foram identificados 238 artigos, 23 preencheram os critérios de inclusão.Os estudos evidenciaram a influência dos lobos frontais no desempenho da MP, mas destes poucos abordaram especificamente a ELF. Foi comparado o desempenho relacionado à MP em pacientes com ELF e ELT (Epilepsia de Lobo Temporal) e ambos demonstraram prejuízos na memória da vida diária. Conclusáo. $\mathrm{O}$ bom desempenho da $\mathrm{MP}$ requer o envolvimento das estruturas frontais. Pacientes com epilepsia frontal podem apresentar prejuízos na sua vida diária, tendo dificuldades que atrapalham sua autonomia e independência.

Unitermos. Epilepsia do Lobo Frontal, Memória, Transtornos da Memória, Neuropsicologia.

Citaçáo. Vasques AM, Gomes RF, Freitas AM. Memória Prospectiva e Epilepsia no Lobo Frontal.

\begin{abstract}
Introduction. Patients with Frontal Lobe Epilepsy (FLE), although generally demonstrate a good performance on traditional memory tests, show many forgetfulness in daily life, compromising their academic, professional and social life. Such forgetfulness is related to the Prospective Memory (PM), which consist in remembering, on the right moment, an intention to be made in the future. Objective. This article has the purpose of review studies related to the prospective memory and its functioning in patients with frontal lobe epilepsy (FLE). Method. Literature review, using database Medline and SciELO, from 2007 to 2011 in the English language, with the words memory, prospective memory and frontal lobe epilepsy. Results. 238 articles were identified, 23 met the inclusion criteria. The studies showed the influence of the frontal lobes in the performance of PM, but from these only few specifically addressed the FLE. It was compared the performance related to PM in patients with FLE and TLE (Temporal Lobe Epilepsy) and both showed losses in daily life memory. Conclusion. The good performance of PM requires the involvement of frontal structures. Patients with frontal epilepsy may present impairments in their daily lives, having difficulties which hinder their autonomy and independence.
\end{abstract}

Keywords. Frontal Lobe Epilepsy, Memory, Memory Disorders, Neuropsychology.

Citation. Vasques AM, Gomes RF, Freitas AM. Prospective Memory and Frontal Lobe Epilepsy.
Trabalho realizado na Pontifícia Universidade Católica doRio Grande do Sul - PUCRS, Porto Alegre-RS, Brasil.

1.Neuropsicóloga, Professora da FSG-RS. Mestre em Medicina e Ciências da Saúde- Neurociências e doutoranda em Geriatria e Gerontologia pela Pontifícia Universidade Católica do Rio Grande do Sul- PUCRS, Porto Alegre, RS, Brasil.

2.Neuropsicóloga, Mestre e Doutoranda em Medicina e Ciências da SaúdeNeurociências pela Pontifícia Universidade Católica do Rio Grande do SulPUCRS, Porto Alegre, RS, Brasil.

3.Psicóloga, Mestre e Doutoranda em Medicina e Ciências da Saúde- Neurociências pela Pontifícia Universidade Católica do Rio Grande do Sul- PUCRS, Porto Alegre, RS, Brasil.
Endereço para correspondência:

Adriana M Vasques AvIpiranga, 6.900

CEP 90610-000, Porto Alegre-RS, Brasil. E-mail: adrivasques@hotmail.com 


\section{INTRODUÇÃO}

A denominação epilepsia provém da palavra grega epilambaneim, que significa surpresa. Trata-se de uma doença crônica, um sinal ou sintoma de um transtorno neurológico que, em geral, se manifesta sob a forma de crises convulsivas recorrentes com grau variável de intensidade e duração ${ }^{1}$.

Estima-se que existam em torno de 60 milhões de pessoas com epilepsia no mundo, enquanto no Brasil, a estimativa é que a epilepsia acometa 1-2\% da população ${ }^{2}$.

Apesar do grande número de estudos relatarem a relação entre epilepsia e transtornos cognitivos, poucos envolvem a Epilepsia do Lobo Frontal (ELF) ${ }^{3}$. Em contraste com o grande número de pesquisas sobre o funcionamento de memória nos pacientes com epilepsia de lobo temporal (ELT), as informações são limitadas e controversas, de modo que sua prevalência e gravidade nesses pacientes permanecem incertas ${ }^{4}$.

No entanto, estudos recentes têm demonstrado déficits na memória de moderados a graves, em pacientes com síndromes epilépticas do lobo frontal ${ }^{5}$. Pesquisadores investigaram o desempenho da memória e das funções executivas em pacientes com epilepsia autossômica dominante do lobo frontal noturna. O desempenho da memória foi mais prejudicado do que as funçôes executivas, resultado também encontrado em estudos menores ${ }^{6}$.

Sendo assim, o presente estudo pretende buscar subsídios na literatura que possibilite aprofundar os conhecimentos acerca dessa memória táo importante para nossa vida diária que acaba por causar grande impacto na rotina dos pacientes com epilepsia frontal.

\section{MÉTODO}

Este é um artigo de revisão de literatura realizado através de pesquisas de artigos e jornais indexados no Medline, Scielo e liga Brasileira de Epilepsia. Nesta pesquisa de artigos os descritores utilizados foram memória prospectiva, epilepsia de lobo frontal, lobo frontal. Os estudos analisados foram os que ocorreram do ano de 2007 a 2011. 238 artigos fizeram parte da busca inicial. Destes, 23 foram utilizados no presente artigo por preencherem os critérios de inclusão, sendo os demais descartados. Os critérios de inclusão adotados foram estudos que relacionavam epilepsia com memória pros- pectiva ou lobo frontal com memória prospectiva.

\section{Epilepsia Frontal}

A ELFé considerada a segunda forma mais comum das epilepsias parciais, depois da epilepsia do lobo temporal (ELT), representando $20 \%$ a $30 \%$ das epilepsias parciais e $15 \%$ das crises refratárias. Aproximadamente um quarto dos pacientes com epilepsia focal refratárias tem $\mathrm{ELF}^{7}$.

Conforme estudo de revisão, as crises frontais se manifestam de forma breve, com início e fim súbitos ${ }^{8}$.

A semiologia clínica da ELF depende da localização e lateralização do foco epileptogênico.

Os lobos frontais são compostos de áreas morfologicamente distintas e interconectadas entre si e com outras regióes corticais posteriores e zonas subcorticais, constituindo circuitos anatômicos de alta complexidade?

\section{Lobos Frontais e Memória}

Os primeiros indícios de perda de memória na epilepsia do lobo frontal originam-se do pós cirúrgico de uma série de casos. Estudos publicados peloInstituto Neurológico de Montreal identificaram déficits de memória em pacientes após ressecçôes do lobo frontal ${ }^{5}$.

Pessoas com memória comprometida apresentam dificuldades para lembrar não somente coisas que aconteceram no passado, como lembrar o que é esperado que façam no futuro ${ }^{10}$.

\section{Memória Prospectiva}

Muitos estudos sobre a memória humana têm sido sobre a memória retrospectiva (MR), enfocando o passado e a capacidade de lembrar-se de eventos ou conhecimentos adquiridos previamente. Em contraste, há a memória prospectiva (MP), que envolve a lembrança de ações que se pretende realizar, sendo a memória para intenções futuras. Ela permite a realização de açóes futuras pretendidas, sem a contínua repetição verbal da ação até o momento adequado ${ }^{11,12}$. Envolve lembrar de executar uma ação específica no momento em que outra atividade está em curso ${ }^{13,14}$. Desse modo, torna-se evidente a importância dessas memórias para um bom desempenho nas atividades diárias, tornando-se crucial para uma vida independente ${ }^{13}$. 
A memória prospectiva é uma função muito utilizada no cotidiano, sendo requisitada tanto emtarefas de curto prazo, como cuidar de desligar uma panela no fogo, como em tarefas de longo prazo episódicas, como se lembrar de dar um recado a um amigo, ou então, em tarefas da rotina, como tomar uma medicação diariamente em um determinado horário ${ }^{14}$.

A MP pode ser explicada como a capacidade de recuperar, no momento oportuno, ainformação referente à realização de uma tarefa no futuro. A MP divide-se em dois tipos: a fundamentada em pistas externas (eventos) e a fundamentada em pistas internas (tempo). A MP baseada no tempo envolve a lembrança de uma ação em determinado horário específico (como exemplo, chegar às $19 \mathrm{~h}$ e $30 \mathrm{~min}$ no encontro agendado). Já a MP baseada em evento requer a lembrança da realização de uma ação nas circunstâncias apropriadas, como por exemplo: transmitir uma mensagem ao ver alguém ${ }^{11}$.

As falhas de memória prospectiva podem ser de grande gravidade, podendo ter sérias consequências, quando o esquecimento não é de apenas um compromisso, mas por exemplo, esquecer o filho dentro do um carro, como ocorreu com um pai atencioso que, após uma mudança na rotina, esqueceu de levar o filho na creche, indo direto seu trabalho (seu trajeto habitual). Isso resultou na morte da criança ${ }^{15}$.

\section{Memória Prospectiva e Lobo Frontal}

Embora seja conhecido e documentado o envolvimento dos lobos frontais nas tarefas relacionadas à memória ${ }^{5}$, são poucos os trabalhos da literatura que abordam o temarelacionando-o com a ELF.

Pacientes com ELF,embora apresentem bom desempenho em testes tradicionais de memória, revelam muitos esquecimentos na vida diária, comprometendo sua vida acadêmica, profissional e social. Tais esquecimentos referem-se à MP, que consiste em recordar, no momento adequado uma intenção a desempenhar no futuro.

As áreas frontais são responsáveis pelos processos cognitivos envolvidos nas tarefas de MP (iniciação e exe- cução de ação, atualização e interrupção da atividade em andamento) ${ }^{16}$.

Estudos de neuroimagemfuncional na MP mostram que a manutençãoda intençãodepende daativação do córtex pré-frontal, lateral frontal ${ }^{17}$ e parietal inferior ${ }^{18}$.

A MP é uma função que requer a contribuição de várias partes do lobo frontal, em especial docórtex pré-frontal, mais especificamente o córtex dorsolateral direito, o córtex ventro-medial direito e o córtex dorsomedial esquerdo $^{19}$.

A MP lida com o cotidiano das pessoas. Estudo realizado mostrou que as pessoas relatavam uma média de 15 planos para a semana seguinte, destes $25 \%$ não chegavam a ser executados ${ }^{20}$.

Conforme estudo realizado ${ }^{21}$ o córtex dorsolateral direito desempenha um papel crucial na MP, enquanto o córtex posterior esquerdo envolve-se em processos posteriores, como a recuperação da ação pretendida.

A MP pode ser avaliada através de registros observacionais, simulações de atividades em contexto semirrealístico, por atividades naturalísticas, por testes neuropsicológicos ou por meio de paradigmas ${ }^{22}$.

Em um estudo comparando pacientes com ELF e ELT, ambos mostraram prejuízos na MP, contrariando a hipótese inicial de que pacientes com ELT teriam um maior comprometimento na memória diária ${ }^{23}$.

\section{CONSIDERAÇÕES FINAIS}

Através dessa revisão, foi verificado que o bom desempenho da MP requer o envolvimento das estruturas frontais. Pacientes com ELF podem apresentar déficits na MP, manifestando prejuízos em sua vida diária. A compreensão do lobo frontal é complexa e poucas são as pesquisas que buscam desvendá-lo. Embora seja documentada a relação entre lobo frontal e déficits de memória, esse tema tem sido pouco explorado comparado com inúmeros estudos que abordam a relação da memória com o lobo temporal. Novas pesquisas são necessárias para compreender os mecanismos dessa interação entre os lobos frontais, epilepsia do lobo frontal e a memória prospectiva. 


\section{REFERÊNCIAS}

1.Acharya M, Hattiangdy B, Shetty A. Progress in neuroprotective strategies for preventing epilepsy. Prog Neurobiol 2008;84:363-404.

http://dx.doi.org/10.1016/j.pneurobio.2007.10.010

2.Noronha AL, Borges MA, Marques LH, Zanetta DM, Fernandes PT, DeBoer $\mathrm{H}$, et al. Prevalence and pattern of epilepsy treatment in different socioeconomic classes in Brazil. Epilepsia 2007;48:880-5.

http://dx.doi.org/10.1111/j.1528-1167.2006.00974.x

3.Patrikelis P, Angelakis E, Gatzonis S. Neurocognitive and behavioral functioning in frontal lobe epilepsy: a review. Epilepsy Behav 2009;14:19-26.

http://dx.doi.org/10.1016/j.yebeh.2008.09.013

4.Centeno M, Thompson PJ, Koepp MJ, Helmstaedter C, Duncan JS. Memory in frontal lobe epilepsy. Epilepsy Res 2010;91:123-32.

http://dx.doi.org/10.1016/j.eplepsyres.2010.07.017

5.Picard F, Pegna, AJ, Arntsberg V, Lucas N, Kaczmarek I, Todica O,et al. Neuropsychological disturbances in frontal lobe epilepsy due to mutated nicotinic receptors. Epilepsy Behav 2009;14:354-9.

http://dx.doi.org/10.1016/j.yebeh.2008.11.003

6.Cho YW, Yi SD, Lim JG, Kim DK. Autosomal dominant nocturnal frontal lobe epilepsy and mild memory impairment associated with CHRNB2 mutation I312M in the neuronal nicotinic acetylcholine receptor. Epilepsy Behav 2008; $13: 361-5$.

http://dx.doi.org/10.1016/j.yebeh.2008.04.017

7.Beleza P, Pinho J. Frontal lobeepilepsy. J ClinNeurosci 2011;18:593-600.

http://dx.doi.org/10.1016/j.jocn.2010.08.018

8.Yacubian E, Kochen S. La semiologia de los lóbulos cerebrales In: Yacubian E, Kochen S, editors. Lascrisis epilépticas. São Paulo: Casa Leitura Médica: 2010, p.37-55.

9.Tirapu-Ustarroz J, Garcia-Molina A, Luna-Lario P, Roig-Rovira T, Pelegrin-Valero C. [Models of executive control and functions. II]. Rev Neurol 2008; $46: 742-50$.

10.Wilson B. Compreendendo a memória e as dificuldades mnemônicas. In: Wilson B, editors. Reabilitaçấo da memória: integrando teoria e prática. Porto Alegre: Artmed: 2011, p.22-37.

11.Eysenck MW, Keane MT. Manual de psicologia cognitiva. $5^{\mathrm{a}}$ ed. Porto Alegre: Artmed: 2007, p.280-5

12.Burgess PW, Gonen-Yaacovi G, Volle E. Functional neuroimaging studies of prospective memory: what have we learnt so far? Neuropsycholo- gia,2011;49:2246-57.

http://dx.doi.org/10.1016/j.neuropsychologia.2011.02.014

13.Rendell PG, Henry JD, Phillips LH, de La Piedad Garcia X, et al. Prospective memory, emotional Valence, and multiple sclerosis.J Clin Exp Neuropsychol 2012;34:738-49.

http://dx.doi.org/10.1080/13803395.2012.670388

14.McDaniel MA, Einstein, GO. An Overview and Synthesis of an Emerging Field. Thousand Oaks: Sage Publications: 2007, 280p.

15.Eysenck MW. A memóriaprospectiva In: Baddeley M, Eysenck MW, Anderson MC,(ed.). Memória. Porto Alegre: Artmed: 2011, p. 363-77.

16.McFarland CP, Gliski EI. Frontal lobe involvement in a task of time-based prpspective memory. Neuropsychologia 2009;47:1660-9.

http://dx.doi.org/10.1016/j.neuropsychologia.2009.02.023

17.Momennejad I, Haynes JD. Human anterior prefrontal córtex encodes the

'What'and 'When'offutur intentions. Neuroimage 2012;61:139-48.

http://dx.doi.org/10.1016/j.neuroimage.2012.02.079

18. Okuda J, Fujii T, Ohtake H, Tsukiura T, Yamadori A, Frith CD, et al. Differential involvement of regions of rostral prefrontal cortex (Brodmann area 10) in time- and event-based prospective memory. Int J Psychophysiol 2007;64:233-46.

http://dx.doi.org/10.1016/j.ijpsycho.2006.09.009

19.Umeda S, Kurosaki Y, Terasawa Y, Kato M, Miyahara Y. Deficits in prospective memory following damage to the prefrontal cortex. Neuropsychologia 2011;49:2178-84.

http://dx.doi.org/10.1016/j.neuropsychologia.2011.03.036

20.Marsh RL, Hicks JL, Landau JD. Event-based prospective memory and executive control of working memory. J ExpPsychol Learn 1998;24:336-49.

http://dx.doi.org/10.1037/0278-7393.24.2.336

21.Bisiacchi PS, Cona G, Schiff S, Basso D. Modulation of a fronto-parietal network in event-based prospective memory: an rTMS study. Neuropsychologia 2011;49:2225-32.

http://dx.doi.org/10.1016/j.neuropsychologia.2011.05.007

22.Adda CC, Catro LH, Além-Mar e Silva LC, Manreza ML, de\&Kashiara R.

Prospective memory and mesial temporal epilepsy associated with hippocampal sclerosis. Neuropsychologia 2008;47:1954-64.

http://dx.doi.org/10.1016/j.neuropsychologia.2008.01.016

23.Cahn-Weiner DA, Wittenberg D, McDonald C. Everyday cognition in temporal lobe and frontal lobe epilepsy. Epileptic Disord 2009;11:222-7. 